\title{
O MERCADO DE TRABALHO NO FUTURO: UMA DISCUSSÃO SOBRE PROFISSÕES INOVADORAS, EMPREENDEDORISMO E TENDÊNCIAS PARA 2020
}

\author{
James Terence Coulter Wright \\ Doutor em Administração de Empresas pela Faculdade de Economia, Administração e Contabilidade \\ da Universidade de São Paulo - FEA/USP \\ Professor da Faculdade de Economia, Administração e Contabilidade da Universidade de São Paulo - \\ FEA/USP \\ jtwright@usp.br
}

\section{Antonio Thiago Benedete Silva}

Mestrando em Administração na Faculdade de Economia, Administração e Contabilidade da Universidade de São Paulo - FEA/USP

Professor do curso de graduação em Administração da Fundação Escola de Comércio Álvares Penteado - FECAP

atbenedete@usp.br

\section{Renata Giovinazzo Spers}

Doutora em Administração Universidade de São Paulo - USP

Professora e coordenadora do Mestrado Profissional de Projetos da Fundação Instituto de Administração - FIA

renatag@fia.com.br

\section{RESUMO}

As inovações tecnológicas, organizacionais e de mercado têm impulsionado profundas transformações no mundo do trabalho. Diversas profissões com conteúdos inovadores estão sendo criadas, visando acompanhar o ritmo das mudanças. Transformações estruturais nas relações de trabalho também têm sido observadas. Como consequência dessas transformações, o empreendedorismo tem sido a alternativa para a geração de emprego e renda. Nesse contexto, esta pesquisa procurou identificar quais serão as profissões mais prováveis de se desenvolver no futuro e onde estarão as oportunidades de negócios para empreendedores, considerando o ano de 2020. Para tanto, foi utilizada a Técnica Delphi, a qual possibilita a identificação de tendências e eventos futuros a partir do uso estruturado do conhecimento de especialistas. Foram realizadas duas rodadas de consulta, com 96 respondentes na Rodada 1 e 112 respondentes na Rodada 2. Os resultados finais apontaram que a ênfase crescente na inovação, a busca por qualidade de vida, o envelhecimento da população e a preocupação com o meio ambiente serão importantes impulsionadores das carreiras mais promissoras nos próximos anos. É vislumbrado um futuro no qual será possível interagir com profissionais como Gerentes de EcoRelações, Chief Innovation Officers e Bioinformacionistas. Quanto ao empreendedorismo, os especialistas projetaram uma participação no mercado de trabalho de $17 \%$ em termos de População Economicamente Ativa. Pelos resultados, é possível apreender que há expectativa de aumento da participação das atividades empreendedoras no mundo do trabalho no futuro, as quais conviverão com as profissões com conteúdos inovadores identificadas no estudo.

Palavras-chave: Técnica Delphi; Profissões do futuro; Empreendedorismo. 


\section{INTRODUÇÃO}

Vista a partir de uma perspectiva global, a mudança nos mercados de trabalho tem sido conduzida por forças poderosas e interconectadas: rápidos avanços e inovações tecnológicas, organizacionais e de mercado e a sua difusão mundial, o aumento do comércio e dos investimentos diretos no exterior, a intensificação da concorrência nos mercados internacionais e, mais recentemente, as alterações climáticas e a necessidade urgente de melhorar a gestão da energia e dos resíduos. Juntas, essas forças têm o potencial de desencadear transformações importantes nos sistemas econômicos em todas as regiões do mundo. As tendências e forças que podem ser identificadas hoje moldarão os trabalhos do futuro. Globalização, envelhecimento da população e tendências sociais, tecnológicas e nos negócios criarão oportunidades para diversas profissões, com nomes que muitas vezes ainda não existem atualmente (Challenger, 2005; Paterson, 2002).

Relatório publicado pela Divisão de Estatísticas do Departamento do Trabalho dos Estados Unidos afirma que os trabalhos de amanhã serão encontrados significativamente no setor de serviços, particularmente relacionados à saúde, comunicação e internet (Crosby, 2002). Áreas relacionadas à estética, cuidados com a saúde e viagens também serão especialmente férteis.

Associado ao mercado de trabalho, um outro fenômeno relevante pode ser identificado: o do empreendedorismo. De acordo com Passos (2007), estudo que mede as taxas do empreendedorismo mundial, o Brasil apresenta um taxa média de atividade empreendedora de 12,8\% da população economicamente ativa, sendo uma das mais altas do mundo. $\mathrm{O}$ trabalhador assalariado formal vem gradativamente assumindo funções típicas do empreendedor e também assumindo os riscos da atividade empreendedora (Passos, 2007).

Uma análise das características do empreendedorismo no Brasil, em 2007, mostra que 48\% dos empreendedores são homens e 52\%, mulheres; 56\% partem para o negócio próprio motivados por uma oportunidade, enquanto $42 \%$ são motivados pela necessidade; no que diz respeito aos setores de atividades, podem ser destacados os de serviços orientados aos consumidores e de transformação que representaram, respectivamente, $54 \%$ e $29 \%$ dos empreendimentos iniciais.

Diante desse contexto, este trabalho procura responder as seguintes questões: quais serão as profissões mais prováveis de se desenvolver no mercado de trabalho no futuro? Onde estarão as oportunidades de negócios para empreendedores? Para tanto, foi realizada uma pesquisa aplicando a Técnica Delphi em duas rodadas de consulta a especialistas, com 96 respondentes na Rodada 1 e 112 respondentes na Rodada 2.

Revista de Administração e Inovação, São Paulo, v. 7, n. 3, p. 174-197, jul./set. 2010 
Segundo a Organização Internacional do Trabalho (OIT, 2001), é necessário melhorar a capacidade de instituições da sociedade para coletar e comunicar informação confiável e atualizada sobre as demandas do mercado de trabalho, como uma base para melhores escolhas dos interessados população, empresas, governos e instituições de ensino - e orientação profissional. Ainda para a OIT, um país precisa ter uma política de desenvolvimento de competências que contemple três objetivos: combinar a procura e a oferta de novas competências; facilitar a adaptação e a mitigação dos seus custos; e manter um dinâmico processo de desenvolvimento. É nesse sentido que os estudos do futuro podem oferecer uma contribuição, na medida em que prospectam tendências, apontam caminhos e oferecem um referencial de discussão para o desenvolvimento de planos estratégicos para que se aja em direção ao futuro desejado.

\section{MERCADO DE TRABALHO NO BRASIL E EMPREGABILIDADE}

Para Chahad (2003), durante a década de 90, intensificou-se um processo de transições experimentado pelo Brasil, com efeitos na estrutura produtiva e, consequentemente, no mercado de trabalho nacional. A abertura comercial, a estabilidade de preços, as privatizações, as inovações tecnológicas e o fenômeno demográfico atuaram conjuntamente na promoção de transformações na estrutura, no funcionamento e na evolução do mercado de trabalho brasileiro. Para o autor, as principais tendências verificadas no mercado de trabalho após a segunda metade da década de 90 foram:

- Crescimento contínuo da PEA, fruto de fortes pressões demográficas;

- Crescimento lento da ocupação total, em virtude, especialmente, das restrições ao trabalho infantil e do jovem (legislação mais severa), e das limitações impostas ao trabalho dos não qualificados (inovação tecnológica e ambiente empresarial altamente competitivo);

- Queda no emprego industrial decorrente do ajuste produtivo (consequência da abertura comercial) e aumento no emprego do setor Serviços (rota para uma sociedade moderna);

- Estagnação do emprego com carteira assinada e aumento de formas atípicas de contratação (assalariado sem carteira assinada) e ocupação (autônomos), em parte refletindo a demanda por flexibilização nas relações de emprego e, também, decorrente da pobreza e miséria, mas, em ambos os casos, originando um aumento da informalidade no mercado de trabalho; 
- Aumento no conjunto de assalariados trabalhando mais que a jornada legal de trabalho, outro reflexo da busca da flexibilização, especialmente por causa da estrutura rígida de encargos trabalhistas;

- Avanço da terceirização da mão de obra, determinado, igualmente, pela busca de relações menos rígidas de emprego que permitam uma redução do custo da mão de obra;

- Forte crescimento do desemprego aberto decorrente tanto das crises de natureza conjuntural, com o intuito de preservar a estabilidade de preços ou defender-se de crises internacionais, quanto de natureza estrutural, fruto do desajuste entre o perfil de mão de obra demandada e a qualidade da oferta de trabalho existente;

- Elevação do chamado desemprego de longo prazo, seja pelo agravamento das oportunidades de emprego derivado do ambiente competitivo imposto pela globalização, seja pela inexistência de um sólido Serviço de Emprego que permita assistir o desempregado em sua busca por trabalho, com uma ampla oferta de serviços;

- Queda acentuada, e generalizada, do rendimento real do trabalhador ocupado assalariado (com ou sem carteira); absorvido pelo setor público ou privado, terceirizado ou não, atuando em atividades de Direção, ou de Execução ou de Apoio; empregado em pequenas ou grandes empresas; ou possuindo pouca ou muita experiência na empresa. Parte dessa queda dos ganhos reais pode ser atribuída à relativa estagnação do PIB, ou ao declínio da atividade econômica, existindo ainda os que acreditam tratar-se da continuidade do processo de flexibilização do mercado de trabalho, na ausência de uma reforma trabalhista ampla.

Diante de todas essas tendências e desafios enfrentados no mercado de trabalho, tem ganhado crescente importância o conceito de empregabilidade. A Organização Internacional do Trabalho (OIT, 2001) define empregabilidade como uma capacidade do indivíduo para assegurar e manter um trabalho digno, para progredir dentro da empresa e entre os empregos, e para fazer face à evolução das tecnologias e condições do mercado de trabalho. Sarsur (2001) afirma que a discussão sobre o termo empregabilidade é relativamente recente no Brasil, com maior destaque a partir dos anos 1990. Para a autora, a empregabilidade pode ser entendida como uma ação individual, que pode ser estimulada ou não pelas organizações, que faz com que profissionais de todos os níveis procurem estar mais bem preparados para enfrentar o mercado de trabalho e suas mutações, pressupondo uma postura proativa, no sentido de qualificar-se permanentemente, em termos de habilidades e capacidades técnicas, 
humanas, conceituais e de relações sociais. Tal ação pressupõe uma maior possibilidade de permanecer num mercado de trabalho crescentemente competitivo e restrito, seja através de um vínculo de emprego formal, assalariado, seja atuando em diferentes organizações, mantendo uma demanda frequente por seus serviços e obtendo, daí, remuneração permanente (Sarsur, 2001). Esse conceito é amplo e abre campo para inserir na discussão um outro conceito fundamental em perspectiva ampliada: a ação empreendedora.

\section{NOVAS FRENTES E PERSPECTIVAS PROFISSIONAIS: O EMPREENDEDORISMO}

Estar engajado em um processo contínuo de ação empreendedora tornou-se uma fonte de vantagem competitiva (Kuratko, 2009). Mas muito se discute sobre o conceito de empreendedorismo.

Para Harper (2008), no nível mais básico, o empreendedorismo envolve a descoberta e a criação de novas soluções e finalidades. Para esse autor, a descoberta empreendedora é definida como um processo de solução de problemas de busca por lucro que acontece em condições de incerteza estrutural, exigindo o exercício de imaginação e julgamento crítico na identificação de problemas (oportunidades) e na geração de soluções para serem testadas. Segundo Shane, Locke e Collins (2003), para que a ação empreendedora seja possível é preciso haver independência. Para os autores, a independência pressupõe o indivíduo assumir a responsabilidade por usar seu próprio julgamento em vez de cegamente seguir as direções de outros. Envolve também assumir a responsabilidade pela sua própria vida em vez de viver dos esforços de outros.

Dornelas (2005) afirma que definições mais abrangentes mostram que o empreendedorismo vai além do ato de abrir novas empresas e que pode estar relacionado a vários tipos de organizações, em vários estágios de desenvolvimento. $\mathrm{O}$ autor resgata as definições clássicas da Harvard Business School e do Babson College. Para a Harvard Business School, o empreendedorismo é a identificação de novas oportunidades de negócio, independentemente dos recursos que se apresentam disponíveis ao empreendedor. Já o Babson College define o termo de forma ainda mais abrangente: o empreendedorismo é uma maneira holística de pensar e de agir. $\mathrm{O}$ ato de empreender está relacionado à identificação, análise e implementação de oportunidades, tendo como foco a inovação e a criação de valor. Nesse sentido, McGrath e MacMillan (2000) enfatizam que, do ponto de vista estratégico, é fundamental a incorporação de um mind-set empreendedor, particularmente em ambientes de competição e mudança de alta velocidade.

Revista de Administração e Inovação, São Paulo, v. 7, n. 3, p. 174-197, jul./set. 2010 
Aplicado ao nível pessoal, ao aproximar o conceito de empregabilidade ao de empreendedorismo, pode-se depreender que a aplicação efetiva da capacidade de se manter empregado está ligada às características empreendedoras, principalmente quando considerada uma maneira holística de pensar e de agir, orientada para a busca de oportunidades. Nessa linha, Harper (2008) enfatiza que o empreendedorismo não se limita à criação de empresas, sendo a firma uma entre várias estruturas de governança para organizar transações econômicas. Para o autor, o empreendedorismo pode estar mais amplamente difundido entre os indivíduos, inclusive dentro de empresas já existentes.

A figura do empreendedor ganhou destaque com Schumpeter (1934), que o descreve como aquele que enfrenta todas as diversidades existentes para realizar uma inovação, contando às vezes muito mais com a intuição do que com seu conhecimento de negócios. Por isso, a atividade empreendedora não poderia ser totalmente ensinada, estando muito mais relacionada a insights e características particulares do empreendedor. Por sua vez, Usher (1988) propôs uma abordagem mecanicista da inovação, que valorizava o papel da educação e dos conhecimentos (acts of skill) do empreendedor na hora de inovar.

Para Erikson (2002), seguindo a linha das características empreendedoras, a criação de uma empresa bem-sucedida requer recursos tangíveis e intangíveis substanciais. Nessa perspectiva, o desafio para empresas emergentes é a capacidade de demonstrar os recursos intangíveis presentes na iniciativa, como capital empreendedor. É a qualidade da capacidade empreendedora, isto é, a capacidade de gerar rendas futuras, que conta para a sua eficiência. É fundamental demonstrar competência e comprometimento, e potencial para comportamento empreendedor sustentável. Além disso, há uma relação dinâmica entre comprometimento e competência: um aumento do nível de competência empreendedora percebida fortalecerá seu comprometimento empreendedor. Por exemplo, indivíduos que percebem uma alta capacidade definem metas mais desafiadoras para si mesmos e possuem um comprometimento mais forte com essas metas.

Filion (1999) acrescenta que o empreendedor é alguém com capacidade de estabelecer objetivos e encontrar oportunidades, e para isso faz uso de sua criatividade e do conhecimento do ambiente no qual se encontra inserido. A orientação de suas decisões é o contínuo aproveitamento de oportunidades por meio de inovações, o que implica assumir riscos moderados. Conforme afirma Drucker (1987), a inovação é o instrumento específico dos empreendedores, o meio pelo qual eles exploram a mudança, como uma oportunidade para um negócio diferente ou um serviço diferente. Segundo o autor, o ambiente oferece fontes importantes para oportunidades empreendedoras, devendose monitorar, por exemplo, mudanças demográficas - definidas como mudanças na população, sua 
grandeza, estrutura etária, composição, emprego, status educacional e renda - que provocam um forte impacto sobre o que será comprado, por quem e em que quantidade (Drucker, 1987).

Assim, profissionais com posturas empreendedoras para as suas carreiras devem monitorar o ambiente e as fontes de inovações e mudanças tanto quando o objetivo é a busca de oportunidades de negócios como quando o objetivo é desenvolver competências para se inserir no mercado de trabalho e, assim, oferecer habilidades requisitadas pelo mercado. Quando considerada, por exemplo, a tendência de elevação do chamado desemprego de longo prazo, provocado pelo agravamento das oportunidades de emprego derivado do ambiente competitivo imposto pela globalização, apontada por Chahad (2003), esse conceito ganha ainda mais importância, reforçado pelo fato de, no Brasil, 42\% dos novos empreendimentos serem motivados pela necessidade (GEM, 2007).

A atuação empreendedora do sexo feminino é proeminente no Brasil. O número de empresas criadas por mulheres é cada vez maior: segundo Passos (2007), as brasileiras ocuparam o $7^{\circ}$. lugar, no ranking mundial como mais empreendedoras, com uma taxa de 12,71\% (aproximadamente 8 milhões). Essas empresas ainda se destacam por apresentarem uma sobrevivência maior do que a média de vida dos novos empreendimentos. Muitos autores acreditam que essas experiências bem-sucedidas de negócios estão intrinsecamente ligadas à forma de liderar das mulheres (Machado, 1999).

Também vale mencionar o papel do jovem empreendedor brasileiro. Em 2006, 54\% das empresas nascentes e 57\% das empresas com menos de três anos tinham à sua frente alguém com menos de 35 anos (Schlemm et al., 2007). É possível ainda que nos próximos anos um número maior de cidadãos decida ser dono do próprio negócio, pois o empreendedorismo é uma das estratégias de agentes públicos para reduzir o desemprego entre jovens (Sela, Sela, \& Franzini, 2006). Nesse sentindo, destaca-se o programa Jovem Empreendedor do governo federal, lançado em 2004, cujo objetivo é criar novas oportunidades de renda para jovens de 18 a 24 anos.

Aplicado ao contexto de criação de empresas, a análise da atividade empreendedora no Brasil revela ser ela 39\% maior que a média mundial, enquanto o crescimento da renda per capita brasileira representa apenas $69 \%$ do valor do crescimento médio mundial da renda per capita. Segundo Passos (2007), o Brasil, como em anos anteriores, demonstrou a grande capacidade empreendedora de sua população ao atingir uma Taxa de Atividade Empreendedora (TAE) de 12,72\% da População Economicamente Ativa (PEA) em 2007. Esse valor o posiciona na 9a colocação entre os 42 países que participaram da pesquisa. O valor da TAE para 2007 é muito semelhante à média dos últimos sete anos de participação do Brasil, que é de 12,83\%. Ao se comparar esse valor à média da TAE para os países que participaram de todas as coletas de 2001 a 2007, pode-se observar que a taxa média brasileira permanece sistematicamente acima da média mundial, ou seja, a população brasileira é em média 
87,61\% mais empreendedora do que o grupo de países que participaram de todas as edições da Pesquisa GEM de 2001 a 2007.

Para explicar esta elevada TAE, pode-se dizer que diante dos altos índices de desemprego e informalidade no mercado de trabalho brasileiro na década de 90, o empreendedorismo encontrou um ambiente favorável para sua disseminação, por isso apresentou-se como alternativa legal aos trabalhadores à época (Lima, 2008).

Complementarmente, contribuiu para o sucesso dessas empresas iniciadas nos anos 1990 e para o surgimento de outras que viriam nos anos seguintes a estabilidade econômica do país. Com ela vieram os itens que Bidhé (2000) definiu como as condições necessárias para que pequenos empreendimentos cresçam, como impostos proporcionais ao tamanho da empresa, pequena concentração de mercado para facilitar a entrada de novos competidores, alta mobilidade de capitais e mão de obra, disponibilidade de crédito, custos fixos relativamente baixos, escala, respeito a propriedade privada e otimismo quanto ao futuro, entre outras qualidades. O Brasil apresenta, em maior ou menor grau, cada um dos atributos mencionados pelo autor.

Em relação aos fatores que inibem o empreendedorismo no Brasil, Passos (2007) apontou que, para os empreendedores, a principal dificuldade é a falta de recursos financeiros, seguida pelas insuficientes políticas governamentais de incentivo, o difícil acesso à infraestrutura física e a dificuldade de conquistar clientes para seus produtos. Especialistas mencionam ainda problemas relacionados à educação e treinamento como barreiras ao desenvolvimento dos negócios. Para Katz (2003), a educação empreendedora continuará uma importante e crescente disciplina acadêmica ao redor do mundo. Graevenitz, Harhoff e Weber (2010) afirmam que são importantes políticas educacionais que veem o treinamento empreendedor como uma maneira de informar os estudantes sobre essa opção de carreira e de criar oportunidades de aprendizagem para calibrar e refinar suas avaliações de quais carreiras são mais apropriadas.

\section{ABORdAGEM METOdOLÓGICA: PROSPECÇÃO DO FUTURO COM A TÉCNICA DELPHI}

Para Wright e Giovinazzo (2000), na sua formulação original, o Delphi é uma técnica para a busca de um consenso de opiniões de um grupo de especialistas a respeito de eventos futuros, baseando-se no uso estruturado do conhecimento e da experiência de um painel de especialistas, no 
pressuposto que o julgamento coletivo, quando organizado adequadamente, é melhor do que a opinião de um só indivíduo. A evolução em direção a um consenso obtido no processo representa uma consolidação do julgamento intuitivo de um grupo de peritos sobre eventos futuros e tendências. A Técnica Delphi passou a ser disseminada no começo dos anos 1960, com base em trabalhos desenvolvidos por Olaf Helmer e Norman Dalker, pesquisadores da Rand Corporation (Estes \& Kuespert, 1976). O objetivo original era desenvolver uma técnica para aprimorar o uso da opinião de especialistas na previsão tecnológica. Na metodologia desenvolvida, isso era feito estabelecendo-se três condições básicas: o anonimato dos respondentes, a representação estatística dos resultados e o feedback de respostas do grupo para reavaliação nas rodadas subseqüentes (Martino, 1993). Ao longo do tempo, o método passou a ser utilizado para previsão de tendências e identificação de políticas e estratégias sobre os mais diversos assuntos.

O Delphi realizado pela internet, segundo Giovinazzo e Fischmann (2001), conserva as mesmas premissas características de uma pesquisa Delphi tradicional, ou seja, são mantidos o anonimato dos respondentes, a representação estatística da distribuição dos resultados e o feedback de respostas do grupo para reavaliação nas rodadas subsequentes, sendo os resultados da primeira rodada divulgados na internet, para que possam ser considerados pelo grupo no preenchimento da segunda rodada. A sequência básica de atividades envolvidas na execução de um Delphi Eletrônico é descrita e ilustrada na Figura 1. 


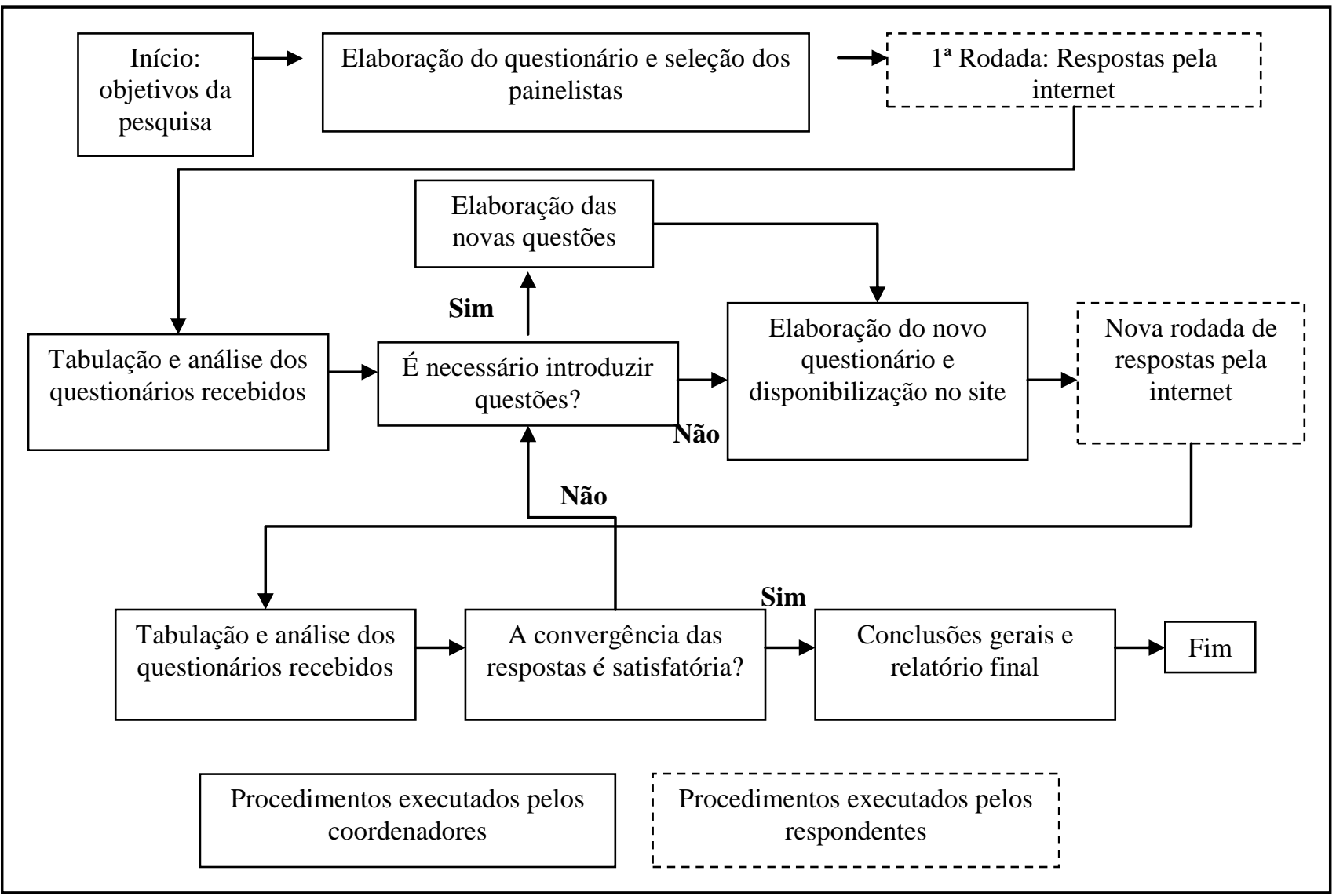

Figura 1- Sequência de Execução de uma Pesquisa Delphi Eletrônica

Fonte: Giovinazzo e Fischmann (2001).

Com base nessa sequência de etapas, inicialmente foi definido o objetivo da pesquisa, o qual deve ser claro, especificando o horizonte de tempo e o tipo de resultado desejado. É importante que o objetivo de pesquisa seja traduzido em necessidades específicas de informação. O objetivo definido para esta pesquisa foi identificar as profissões mais prováveis de se desenvolver no futuro e onde estarão as oportunidades de negócios para empreendedores, considerando o ano de 2020.

Em seguida foi realizada uma coleta de dados secundários com análise de vasta literatura sobre o tema, tendo em vista compor o questionário. Tal revisão contemplou fontes especializadas no tema, como a revista The Futurist, a Organização Internacional do Trabalho (OIT) e sites na internet de órgãos governamentais responsáveis pela implementação de políticas públicas relacionadas ao mercado de trabalho. Nessa pesquisa, o questionário foi elaborado com questões abertas e fechadas.

No que se refere à seleção dos painelistas, a pesquisa contou com um grupo de formação multidisciplinar, atuantes no mercado de trabalho e reconhecidamente conhecedores de tendências para profissões e oportunidades de negócios. Conforme afirmam Giovinazzo e Fischmann (2001), a 
qualidade do resultado depende essencialmente dos participantes do estudo. Para esta pesquisa, especificamente, foram realizadas duas rodadas de consulta a especialistas, com 96 respondentes na Rodada 1 e 112 respondentes na Rodada 2. O Quadro 1 apresenta o perfil dos participantes.

\begin{tabular}{l|c|c|c|l|c|c|c}
\hline \multicolumn{3}{l}{ RODADA 1 } & \multicolumn{5}{c}{ RODADA 2 } \\
\hline Formação Acadêmica & $(\%)$ & Cargo & $(\%)$ & $\begin{array}{l}\text { Formação } \\
\text { Acadêmica }\end{array}$ & $(\%)$ & Cargo & $(\%)$ \\
\hline Graduação & 13 & Analista & 13 & Graduação & 11 & Analista & 5 \\
\hline Mestrado & 19 & Gerente & 22 & Mestrado & 16 & Gerente & 39 \\
\hline Doutorado & 8 & Diretor & 31 & Doutorado & 6 & Diretor & 33 \\
\hline Pós-Doutorado & 1 & Professor & 12 & Pós-Doutorado & 1 & Professor & 10 \\
\hline Livre-docente & 1 & Sócio & 16 & Livre-docente & 1 & Sócio & 7 \\
\hline MBA/especialização & 58 & Consultor & 5 & MBA/especialização & 65 & Consultor & 5 \\
\hline Quadro 1- Perfli dos Especialistas da Pesqu
\end{tabular}

Quadro 1- Perfil dos Especialistas da Pesquisa Delphi

Fonte: Elaborado pelos autores.

A etapa seguinte foi a coleta de dados, para a qual o questionário foi disponibilizado em um site na internet, utilizando um formulário cujos dados das respostas foram encaminhados para uma planilha eletrônica do Excel. Nessa etapa, os respondentes foram comunicados por e-mail e preencheram o questionário diretamente pela internet.

Em seguida, os dados foram coletados e tabulados, aplicando-se técnicas estatísticas descritivas. Especificamente, nas questões fechadas, utilizou-se o cálculo de frequência, mediana e quartis. Nas questões abertas, fez-se uso da Análise de Conteúdo, procurando associar os principais argumentos às diferentes tendências das respostas.

Tendo em vista consolidar os resultados e busca um consenso entre os especialistas consultados, procedeu-se em seguida a realização da Rodada 2 da pesquisa, cujo questionário apresentou os resultados da Rodada 1, possibilitando que cada respondente reveja sua posição diante da previsão e argumentação do grupo, em cada pergunta. A Rodada 2 foi, da mesma forma que a primeira, disponibilizada na internet. Assim, como na Rodada 1, os dados foram coletados e analisados, utilizando-se, nas questões fechadas, o cálculo da frequência, mediana e quartis. Nas questões abertas, fez-se uso da Análise de Conteúdo.

Os resultados obtidos com as duas rodadas da pesquisa são apresentados a seguir. 


\section{RESULTADOS}

Considerando os desafios enfrentados no mercado de trabalho - impostos por forças como a inovação tecnológica e a globalização, apenas para citar duas com impactos significativos na sociedade -, profissionais terão que desenvolver continuamente suas competências e estar atentos à evolução de tendências que determinarão as demandas por profissionais no futuro. Adicionalmente, quando se observa o crescimento da terceirização e a busca de relações de trabalho mais flexíveis (Chahad, 2003), por exemplo, o empreendedorismo torna-se alternativa de carreira para muitos profissionais enfatizando agora a necessidade de perceber oportunidades (Dornelas, 2005; Filion, 1999). Diante desse contexto, os resultados sobre profissões inovadoras emergentes e oportunidades para empreendedores no futuro vão de encontro ao conceito de empregabilidade - em que o objetivo é permanecer num mercado de trabalho crescentemente competitivo e restrito, seja através de um vínculo de emprego formal, assalariado, seja atuando em diferentes organizações, mantendo uma demanda frequente por seus serviços e obtendo, daí, remuneração permanente (Sarsur, 2001).

\subsection{PROFISSÕES DO FUTURO}

Na Rodada 1, a partir de uma lista de 30 profissões, os especialistas indicaram 10 carreiras novas e emergentes como as mais prováveis de terem espaço crescente no mercado de trabalho, considerando o ano de 2020.

Já na Rodada 2 foi solicitado que, a partir da lista de 20 carreiras mais indicadas na Rodada 1, indicassem as 6 carreiras mais prováveis de se desenvolverem. O Quadro 2 mostra os resultados obtidos nas Rodadas 1 e 2.

\begin{tabular}{c|l|c|c}
\hline \multicolumn{1}{c|}{ PROFISSÕES } & \multicolumn{1}{|c|}{ DESCRIÇÃo } & $\begin{array}{c}\text { RODADA 1 } \\
\text { \% de } \\
\text { respondentes }\end{array}$ & $\begin{array}{c}\text { RODADA 2 \% de } \\
\text { respondentes }\end{array}$ \\
\hline Gerente de Eco-Relações & $\begin{array}{l}\text { Profissional que irá se comunicar e } \\
\text { trabalhar com consumidores, grupos } \\
\text { ambientais e agências governamentais } \\
\text { para desenvolver e maximizar programas } \\
\text { ecológicos. }\end{array}$ & 67 & $\mathbf{7 2}$ \\
\hline Chief Innovation Officer & $\begin{array}{l}\text { Interagirá com os funcionários em } \\
\text { diferentes áreas da organização para } \\
\text { pesquisar, projetar e aplicar inovações. }\end{array}$ & 63 & $\mathbf{6 7}$ \\
\hline Gerente de Marketing e- & $\begin{array}{l}\text { Gerencia o desenvolvimento e } \\
\text { implementação de estratégias de sites na } \\
\text { Commerce }\end{array}$ & 47 & $\mathbf{4 6}$ \\
\hline \hline
\end{tabular}

Revista de Administração e Inovação, São Paulo, v. 7, n. 3, p. 174-197, jul./set. 2010 


\begin{tabular}{|c|c|c|c|}
\hline Conselheiros de Aposentadoria & $\begin{array}{l}\text { Profissionais responsáveis por ajudar a } \\
\text { planejar a aposentadoria. }\end{array}$ & 50 & 39 \\
\hline $\begin{array}{c}\text { Coordenador de } \\
\text { Desenvolvimento da Força de } \\
\text { Trabalho e Educação } \\
\text { Continuada }\end{array}$ & $\begin{array}{l}\text { Coordenador responsável por gerenciar } \\
\text { programas para ajudar funcionários } \\
\text { qualificados a atingir níveis avançados em } \\
\text { suas áreas de especialização. }\end{array}$ & 44 & 35 \\
\hline "Bioinformacionistas" & $\begin{array}{l}\text { Cientistas que trabalharão com } \\
\text { informação genética, servindo como uma } \\
\text { ponte para cientistas que trabalham com o } \\
\text { desenvolvimento de medicamentos e } \\
\text { técnicas clínicas. }\end{array}$ & 54 & 34 \\
\hline Técnico em Telemedicina & $\begin{array}{l}\text { Fará parte de uma equipe que oferecerá } \\
\text { tratamento médico e diagnóstico para } \\
\text { pessoas em áreas remotas. }\end{array}$ & 45 & 34 \\
\hline Gerente de Propaganda On-line & $\begin{array}{l}\text { Desenvolve, implementa e gerencia a } \\
\text { estratégia de propaganda com a utilização } \\
\text { de sites na internet. }\end{array}$ & 42 & 27 \\
\hline $\begin{array}{c}\text { Coordenador de Terceirização } \\
\text { Offshore }\end{array}$ & $\begin{array}{l}\text { Profissional responsável por verificar se } \\
\text { os fornecedores terceirizados estão } \\
\text { mantendo determinados padrões, além de } \\
\text { prospectar novas oportunidades de } \\
\text { terceirização. }\end{array}$ & 33 & 27 \\
\hline Chief Health Officer & $\begin{array}{l}\text { Profissional responsável pelo } \\
\text { estabelecimento de programas para } \\
\text { cuidados com a saúde e reavaliação do } \\
\text { sistema de seguros da companhia. }\end{array}$ & 43 & 27 \\
\hline Especialistas em Simplicidade & $\begin{array}{l}\text { Profissionais que simplificarão e } \\
\text { melhorarão a eficiência da tecnologia da } \\
\text { corporação. }\end{array}$ & 40 & 26 \\
\hline Conselheiro Genético & $\begin{array}{l}\text { Identificam e dão suporte para famílias } \\
\text { que têm membros com desordens } \\
\text { genéticas ou aquelas que podem ter o } \\
\text { risco de uma variedade de condições e } \\
\text { predisposições. }\end{array}$ & 41 & 22 \\
\hline Analistas de Networking & $\begin{array}{l}\text { Pesquisarão o verdadeiro fluxo de poder } \\
\text { dentro de uma companhia. }\end{array}$ & 36 & 19 \\
\hline "Geomicrobiologistas" & $\begin{array}{l}\text { Profissionais que unem geologia, ciências } \\
\text { do meio ambiente e microbiologia para } \\
\text { estudar como microorganismos podem } \\
\text { ajudar a fazer novos medicamentos e } \\
\text { limpar a poluição. }\end{array}$ & 31 & 17 \\
\hline Gerente de Diversidade & $\begin{array}{l}\text { Executivo responsável por assegurar que } \\
\text { nenhum grupo na empresa está sendo } \\
\text { tratado com preconceito. }\end{array}$ & 35 & 14 \\
\hline $\begin{array}{l}\text { Coordenador de Experiências } \\
\text { Educacionais }\end{array}$ & $\begin{array}{l}\text { Criam métodos de aprendizagem que } \\
\text { possam ser acessados de diferentes } \\
\text { formas - como a Web. }\end{array}$ & 26 & 14 \\
\hline Age Adviser & $\begin{array}{l}\text { Conciliará desacordos entre grupos de } \\
\text { diferentes idades dentro das empresas e } \\
\text { assegurar que cada departamento tenha } \\
\text { um mix adequado de diferentes gerações. }\end{array}$ & 30 & 14 \\
\hline Web Producer & $\begin{array}{l}\text { Desenvolve, implementa e mantém } \\
\text { aplicações de Web para sites de e- } \\
\text { Commerce consistente com a estratégia e } \\
\text { imagem da companhia. }\end{array}$ & 35 & 13 \\
\hline $\begin{array}{l}\text { Planejador de Reconstituição de } \\
\text { Sistemas }\end{array}$ & $\begin{array}{l}\text { Desenvolve, projeta, testa e implementa } \\
\text { procedimentos para proteger as atividades } \\
\text { dos sistemas de informação no caso de }\end{array}$ & 27 & 6 \\
\hline
\end{tabular}

Revista de Administração e Inovação, São Paulo, v. 7, n. 3, p. 174-197, jul./set. 2010 


\begin{tabular}{c|l|c|c}
\hline & emergências ou desastres. & & \\
\hline Historiador Corporativo & $\begin{array}{l}\text { Profissional responsável por resgatar } \\
\text { projetos, programas, problemas, soluções } \\
\text { e resultados da organização. }\end{array}$ & 21 & 4 \\
\hline
\end{tabular}

\section{Quadro 2: Resultados da Pesquisa Delphi: Profissões mais Promissoras no Futuro}

Fonte: Elaborado pelos autores.

Na Rodada 1, a partir da técnica de análise de conteúdo, foi possível identificar as tendências descritas abaixo como as impulsionadoras das carreiras do futuro. $\mathrm{Na}$ Rodada 2, foi solicitado que os especialistas indicassem as tendências mais fortes consoantes com as carreiras apontadas, visto que tais tendências, conforme indicado nas justificativas, não atuarão de forma isolada e sim interdependente. Isso significa que a ação de uma pode ter efeito sobre as outras, como, por exemplo, a busca de qualidade de vida e preocupação com o meio ambiente pressionando por inovações em diversas áreas.

Com $38 \%$ dos respondentes da Rodada 2, a ênfase crescente na inovação foi a tendência propulsora de novas profissões mais apontada pelos especialistas, tendo em vista que a inovação será um fator cada vez mais crítico para a competitividade das empresas, colocando ênfase no desenvolvimento tecnológico, na educação continuada e no desenvolvimento de novos conhecimentos. Haverá maior consciência quanto à manutenção da capacidade produtiva e intelectual das pessoas, ampliando a longevidade profissional e, portanto estendendo o período de formação, o que promoverá soluções em educação para outras faixas etárias.

As áreas de Biotecnologia, Nanotecnologia, Saúde e Medicina serão especialmente promissoras. O desenvolvimento tecnológico exigirá cada vez mais profissionais capacitados para transformar as inovações tecnológicas em negócios e em aplicações rentáveis. Nesse contexto, inserem-se novas profissões como Chief Innovation Officer, Coordenador de Desenvolvimento da Força de Trabalho e Educação Continuada, Bioinformacionistas, Técnico em Telemedicina e Conselheiro Genético.

A segunda tendência mais apontada foi a busca por qualidade de vida com $26 \%$ dos respondentes da Rodada 2.

As pessoas demandarão serviços que facilitem as suas vidas e tragam comodidade. $\mathrm{O}$ crescimento da internet, com mais pessoas tendo acesso, mais pessoas fazendo compras pela rede e pesquisas. A empresa que desejar permanecer no mercado terá cada vez mais que ter endereços eletrônicos, serviços de atendimento ao cliente e atendimento on-line. Gerente de Marketing eCommerce e Gerente de Propaganda On-line foram apontadas como possíveis profissões relacionadas com a Busca por Qualidade de Vida.

Revista de Administração e Inovação, São Paulo, v. 7, n. 3, p. 174-197, jul./set. 2010 
Em seguida, 18\% dos respondentes da Rodada 2 apontaram como tendência impulsionadora a preocupação com o meio ambiente. Haverá pressão pela busca de alternativas de baixo impacto ambiental, seja na fase de desenvolvimento, produção/processo, seja na fase de descarte ou, no limite, na redução da poluição resultante. Relacionados a essa tendência associam-se o Gerente de EcoRelações e Geomicrobiologistas.

Por último, pode-se apontar como tendência importante o envelhecimento da população (12\% dos respondentes da Rodada 2). O aumento da expectativa de vida da população criará a oportunidade para carreiras relacionadas a atividades e prestação de serviços como: aconselhamento de aposentadoria, planos para gestão dos recursos financeiros, cuidados médicos, atividades culturais e manutenção da vida de idosos. É possível, portanto, o desenvolvimento de profissionais como o Conselheiro de Aposentadoria e o Age Adviser, cujas definições estão descritas no Quadro $2 .$.

Assim como nas profissões emergentes, foram prospectadas áreas profissionais tradicionais e que serão promissoras no futuro. Na Rodada 1, a partir de uma lista de 30 áreas profissionais e de literatura analisada, os especialistas indicaram 10 áreas tradicionais como as mais prováveis de terem espaço crescente no mercado de trabalho, considerando o ano de 2020. Na Rodada 2, foi solicitado que, a partir da lista de 20 áreas mais indicadas na Rodada 1, indicassem as 6 carreiras mais prováveis de se desenvolverem, cujos resultados são apresentados na Tabela 1.

\begin{tabular}{l|c|c}
\hline \multicolumn{1}{c|}{ ÁREAS PROFISSIONAIS } & $\begin{array}{c}\text { RODADA 1 } \\
\text { \% de respondentes }\end{array}$ & $\begin{array}{c}\text { RODADA 2 } \\
\text { respondentes }\end{array}$ \\
\hline Engenharia Ambiental & 81 & 81 \\
\hline Relações Internacionais & 77 & 69 \\
\hline Lazer e Turismo & 66 & 53 \\
\hline Engenharia de Alimentos & 60 & 39 \\
\hline Engenharia de Computação & 60 & 39 \\
\hline Farmácia-Bioquímica & 56 & 36 \\
\hline Administração de Empresas & 60 & 28 \\
\hline Engenharia Agronômica & 37 & 25 \\
\hline Engenharia Mecatrônica & 40 & 25 \\
\hline Engenharia de Materiais & 39 & 17 \\
\hline Direito & 40 & 16 \\
\hline Psicologia & 37 & 15 \\
\hline Publicidade e Propaganda & 33 & 13 \\
\hline Oceanografia & 26 & 13 \\
\hline Engenharia Química & 25 & 11 \\
\hline Educação Física & 26 & 11 \\
\hline Engenharia de Petróleo & 21 & 10 \\
\hline Economia & 36 & \\
\hline
\end{tabular}




\begin{tabular}{l|l|l}
\hline Engenharia de Produção & 20 & 8 \\
\hline Enfermagem & 18 & 5 \\
\hline
\end{tabular}

Tabela 1 - Áreas Profissionais mais Promissoras 2009-2020.

Fonte: Elaborado pelos autores.

As áreas profissionais apontadas acompanham algumas tendências que foram listadas pelos respondentes, conforme síntese abaixo.

A preocupação com o meio ambiente (39\% dos respondentes da Rodada 2) se desdobrará na busca de processos e materiais mais ecológicos. Áreas de estudo relacionadas à produção, conservação e transformação de forma eficiente dos recursos naturais para uso do ser humano terão uma grande demanda graças à crescente conscientização sobre a possibilidade de extinção dos recursos, bem como a irreparabilidade de danos ao ambiente e suas consequências sobre a qualidade de vida na Terra. As áreas profissionais relacionadas serão: Engenharia Ambiental, Engenharia Agronômica, Engenharia de Alimentos e Engenharia de Materiais.

Na sequência, a globalização (31\% dos respondentes da Rodada 2) pressionará as organizações cada vez mais para buscar excelência em performance. Além disso, serão necessários profissionais para realizar operações em nível mundial, necessitando habilitação em negociações internacionais e economia. Como áreas profissionais relacionadas, figuram Relações Internacionais, Administração de Empresas, Direito e Economia.

A qualidade de vida foi apontada por $9 \%$ dos respondentes da Rodada 2, por sua alta importância na vida das pessoas, e qualquer profissão com foco em qualidade de vida terá uma demanda maior. Profissionais de Lazer e Turismo, Psicologia e Educação Física inserem-se nessa tendência.

A virtualização figura com $6 \%$ dos respondentes da segunda rodada. As relações humanas passarão por uma fase mais intensa, embora elas ocorram em grande parte através de sistemas baseados em Tecnologias da Informação e Comunicação. Esse incremento de interatividade demandará profissionais que criem e facilitem a vida das pessoas nesse contexto. Administração de Empresas e Engenharia da Computação mostram-se como as prováveis áreas relacionadas.

Por fim, o envelhecimento da população ( $6 \%$ dos respondentes - Rodada 2), cujas áreas profissionais relacionadas são Farmácia-bioquímica e Enfermagem, também recebe atenção. Uma população cada vez mais velha abre oportunidades para profissões da senioridade, estando relacionadas a cuidados aos mais velhos e desenvolvimento de novos medicamentos. 


\subsection{EMPREENDEDORISMO}

Tendo em vista que o Brasil apresentou um taxa média de atividade empreendedora (TAE) de $12,8 \%$ da população economicamente ativa no período 2001-2007, os especialistas fizeram as seguintes projeções para a participação do empreendedorismo em 2020, conforme mostra a Tabela 2.

\begin{tabular}{c|c|c}
\hline MEDIDA ESTATÍSTICA & $\begin{array}{c}\text { PROJEÇÃO DA TAE EM 2020 } \\
\text { (\%) RODADA 1 }\end{array}$ & $\begin{array}{c}\text { PROJEÇÃO DA TAE EM 2020 } \\
\text { (\%) RODADA 2 }\end{array}$ \\
\hline Primeiro Quartil & 15 & 15 \\
\hline Valor Mediano & 17 & 17 \\
\hline Terceiro Quartil & 20 & 20 \\
\hline
\end{tabular}

\section{Tabela 2- Previsão da TAE em 2020}

Fonte: Elaborado pelos autores.

Pelos resultados, é possível apontar uma expectativa de aumento da participação das atividades empreendedoras, uma vez que todos os quartis apontam uma Taxa de Atividade Empreendedora maior que a atual. As seguintes tendências justificam as projeções realizadas pelos especialistas apontadas na Rodada 1 e priorizadas na Rodada 2.

A tendência de uma nova configuração nas relações de trabalho, escolhida por $54 \%$ dos respondentes da Rodada 2, indica que tais relações sofrerão alterações significativas. Haverá uma diminuição dos postos de trabalho formais, sendo assim, muitos profissionais terão que criar seu próprio emprego. Novas formas de venda das habilidades individuais surgirão e estarão cada vez mais direcionadas às formas autônomas. Junto a essa tendência, indicada por $21 \%$ dos respondentes (Rodada 2), temos a melhoria da educação e ênfase na formação de empreendedores, isto é, a melhora da educação e dos índices sociais, além do incentivo e orientação do governo e de órgãos como o Serviço de Apoio às Micro e Pequenas Empresas (SEBRAE), impulsionando a atividade empreendedora no Brasil e as projeções para mais profissionais com ensino superior, além de um número maior de palestras, seminários, revistas e livros sobre o assunto.

Empresas, universidades e outras instituições de ensino enfatizarão crescentemente a necessidade de empreender, preparando profissionais e desenvolvendo as competências e habilidades necessárias. Contudo, há fatores que contribuem negativamente para esse progresso, por isso $17 \%$ dos respondentes da Rodada 2 apontam possíveis limitadores para o aumento do empreendedorismo 
como outra tendência. O principal argumento é que há uma relação de dependência entre o aumento da TAE e a taxa de juros, o acesso ao capital de risco e a redução nos entraves legais e tributários.

Por último, 7\% dos respondentes da Rodada 2 afirmaram que algumas Motivações pessoais também interferem, dentre elas: busca por satisfação pessoal e independência, aumento da renda familiar e busca de alternativa de trabalho após a aposentadoria.

Diante desse contexto, o desafio passa a ser encontrar oportunidades para o desenvolvimento de novos negócios. Conforme afirma Filion (1999), o empreendedor é alguém com capacidade de estabelecer objetivos e encontrar oportunidades, e para isso faz uso de sua criatividade e conhecimento do ambiente no qual se encontra inserido. Nessa perspectiva, essa pesquisa investigou a percepção dos especialistas consultados quanto ao setor da economia que mais abrigará oportunidades de negócios no futuro. Os resultados mostraram que o setor da economia que deverá gerar mais oportunidades para atividades empreendedoras até 2020, segundo os respondentes da Rodada 1, será o setor de serviços, segundo 95\% dos respondentes, conforme mostra o Gráfico 1. Importante ressaltar que o grupo de especialistas consultados chegou a um consenso sobre as questões sobre empreendedorismo já na Rodada 1 da pesquisa. Com isso, na Rodada 2 não foi solicitado que os especialistas revissem a sua posição.

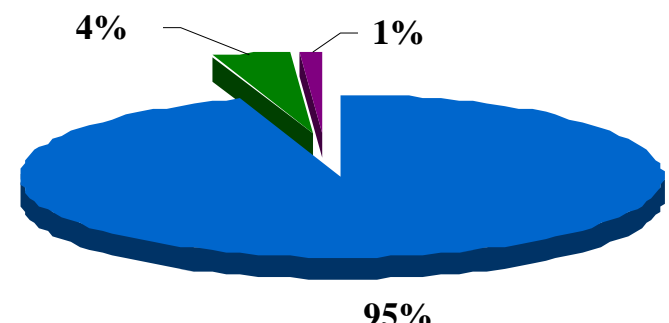

Serviços

Comércio

Indústria

\section{Gráfico 1- Setores segundo potencial empreendedor em 2020}

Fonte: Elaborado pelos autores.

As oportunidades de negócios mais atrativas para o empreendedorismo estarão em áreas como Saúde e Qualidade de Vida, Turismo e Lazer e Serviços para a Terceira idade. Ehlers (2007) complementa destacando que é nítido o desenvolvimento em curso de um novo ciclo econômico baseado em atividades que envolvam um relacionamento mais harmonioso com a natureza. Nessa fase, 
é crucial o papel dos empreendedores que criam novos negócios relacionados à sustentabilidade, tornando-se importantes na conservação do patrimônio natural:

\begin{tabular}{c|l}
\hline ÁREAS & \multicolumn{1}{c}{ ATIVIDADES } \\
\hline Saúde e Qualidade de Vida & $\begin{array}{l}\text { Estética e rejuvenescimento; Saúde Pessoal; Terapias } \\
\text { Alternativas; Saúde da Família; Terceirização de Atividades Domésticas. }\end{array}$ \\
\hline Turismo e Lazer & $\begin{array}{l}\text { Pequenas pousadas; Atividades de lazer programadas para atender hotéis; } \\
\text { Assessoria em viagens internacionais; Turismo focado em estilos de vida. }\end{array}$ \\
\hline Serviços para a Terceira Idade & $\begin{array}{l}\text { Cuidados com os idosos; Serviços previdenciários e atuariais; Geriatria e } \\
\text { Gerontologia. }\end{array}$ \\
\hline Consultorias especializadas & $\begin{array}{l}\text { Sustentabilidade; Bem-Estar; Desenvolvimento de Carreira; Consultoria } \\
\text { Pessoal; Planejamento Financeiro; Consultoria Empresarial. }\end{array}$ \\
\hline Serviços com Base em Tecnologia & $\begin{array}{l}\text { Novos produtos da informação; Desenvolvimento de Softwares; Comunicação } \\
\text { Digital; Otimização e Integração de Processos Empresariais com Uso da Web. }\end{array}$ \\
\hline Alimentação & Reciclagem de Lixo. \\
\hline Ensino & $\begin{array}{l}\text { Alimentos Personalizados - para atender clientes com restrições alimentares, } \\
\text { etc.; Produção de Alimentos Orgânicos. }\end{array}$ \\
\hline Educação à Distância
\end{tabular}

\section{Quadro 3 - Oportunidades de negócios para empreendedores.}

Fonte: Elaborado pelos autores.

Segundo Drucker (1987), o ambiente oferece fontes importantes para oportunidades empreendedoras, devendo-se monitorar mudanças demográficas, econômicas, sociais e tecnológicas, uma vez que provocam um forte impacto sobre o que será comprado, por quem e em que quantidade. Nessa perspectiva, os especialistas indicaram a demanda por serviços cada vez mais personalizados, a busca por qualidade de vida, as pessoas com tempo cada vez mais escasso e o envelhecimento populacional como importantes tendências no ambiente que serão impulsionadoras do desenvolvimento de novos produtos e serviços.

\section{CONCLUSÕES}

Diante dos desafios enfrentados no mercado de trabalho, profissionais terão que desenvolver continuamente suas competências e estar atentos à evolução de tendências que determinarão as demandas por profissionais no futuro. Empreendedores por sua vez devem estar sempre atentos a inovações tecnológicas, novos recursos e novas tendências que podem redirecionar o rumo dos seus 
negócios, tornando as empresas e as tecnologias atuais obsoletas, no processo que Schumpeter (1934) chamou de destruição criativa. Quando se observa o crescimento da terceirização e a busca de relações de trabalho mais flexíveis (Chahad, 2003), por exemplo, o empreendedorismo torna-se alternativa de carreira para muitos profissionais.

Adicionalmente, é vital ressaltar que a noção de empreendedorismo no campo profissional deve ser entendida em uma perspectiva ampliada. Profissionais precisam ter posturas empreendedoras em suas carreiras, devendo monitorar o ambiente, fontes de inovações e mudanças tanto quando o objetivo é a busca de oportunidades de negócios como quando o objetivo é desenvolver competências para se inserir no mercado de trabalho e, assim, oferecer habilidades requisitadas pelo mercado. Diante desse contexto, a noção de empregabilidade se interconecta com o conceito de empreendedorismo, na medida em que profissionais de todos os níveis devem procurar estar mais bem preparados para enfrentar o mercado de trabalho e suas mutações, pressupondo uma postura proativa, no sentido de qualificar-se permanentemente, com o claro objetivo de permanecer num mercado de trabalho crescentemente competitivo e restrito, seja através de um vínculo de emprego formal, assalariado ou atuando em diferentes organizações, mantendo uma demanda frequente por seus serviços e obtendo, daí, remuneração permanente (Sarsur, 2001). Buscar constante qualificação e atingir o objetivo de permanecer no mercado envolve características empreendedoras, principalmente quando considerada uma maneira holística de pensar e de agir, ou seja, de perceber a realidade.

Nessa perspectiva, e considerando a recomendação da OIT (2001) sobre a necessidade de melhorar a capacidade de instituições da sociedade para coletar e comunicar informação confiável e atualizada sobre as demandas do mercado de trabalho, esta pesquisa Delphi procurou responder quais serão as carreiras do futuro e onde estarão as oportunidades de negócios para empreendedores, considerando o ano de 2020. Para tanto, foram realizadas duas rodadas de consulta a especialistas, com 96 respondentes na Rodada 1 e 112 respondentes na Rodada 2.

Os resultados finais apontaram que a ênfase crescente na inovação, a busca por qualidade de vida e a preocupação com o meio ambiente serão importantes impulsionadores na determinação das carreiras mais promissoras nos próximos anos. É vislumbrado um futuro no qual será possível interagir com profissionais como Gerentes de Eco-Relações, Chief Innovation Officers e Bioinformacionistas.

Quanto ao empreendedorismo, os especialistas projetaram uma participação no mercado de trabalho de $17 \%$ em termos de População Economicamente Ativa. Pelos resultados, é possível apreender que há uma expectativa de aumento da participação das atividades empreendedoras no mundo do trabalho, uma vez que todos os quartis apontaram uma Taxa de Atividade Empreendedora 
maior que a atual (12,8\%). As principais tendências que justificam as projeções realizadas pelos especialistas são: nova configuração nas relações de trabalho (54\% dos respondentes) e melhoria da educação e ênfase na formação de empreendedores (21\% dos respondentes). O setor de serviços abrigará o maior número de oportunidades para novos empreendimentos, segundo $95 \%$ dos especialistas pesquisados, visto que essas oportunidades serão em áreas como Saúde e Qualidade de Vida, Turismo e Lazer e Serviços para a Terceira Idade, as quais serão impulsionadas por tendências como busca por qualidade de vida, as pessoas com tempo cada vez mais escasso e o envelhecimento populacional.

Estes resultados apontam quais serão as profissões mais prováveis de se consolidarem no mercado de trabalho no futuro e onde estarão as oportunidades de negócios para empreendedores, até 2020. Cabe destacar que também foi possível identificar grandes tendências sociais, econômicas e tecnológicas que justificam as oportunidades de carreiras e empreendedorismo.

\section{REFERÊNCIAS}

Bidhé, A. V. (2000). The origin and evolution of new businesses. New York: Oxford University Press.

Chahad, J. P. Z. (2003). Tendências recentes no mercado de trabalho: pesquisa de emprego e desemprego. São Paulo em Perspectiva, 17(3-4), 205-217.

Challenger, J. A. (2005). Working in the future. The Futurist, 39(6), 47-50.

Crosby, O. (2002). New and emerging occupations. Occupational Outlook Quaterlly, 46(3), 17-25.

Dornelas, J. C. A. (2005). Empreendedorismo: transformando idéias em negócios. Rio de Janeiro: Campus.

Drucker, P. F. (1987). Inovação e espírito empreendedor. São Paulo: Pioneira.

Ehlers, E. (2007). Empreendedorismo e conservação ambiental no interior de São Paulo. Revista de Economia e Sociologia Rural, 45(1), 185-203.

Erikson, T. (2002). Entrepreneurial capital: the emerging venture's most important asset and competitive advantage. Journal of Business Venturing, 17(3), 275-290.

Estes, G. M., \& Kuespert, D. (1976). Delphi in industrial forecasting. Chemical and Engineering News, 53, 40-47. 
Filion, L. J. (1999). Empreendedorismo: empreendedores e proprietários-gerentes de pequenos negócios. Revista de Administração da USP, 34(2), 05-28.

Giovinazzo, R. A., \& Fischmann, A. A. (2001). Delphi eletrônico - uma experiência de utilização da metodologia de pesquisa e seu potencial de abrangência regional [CD-ROM]. Anais do Congreso Latinoamericano de Estratégia, 14. Buenos Aires.

Global Entrepreneurship Monitor (2006). Empreendedores no Brasil - 2005. Recuperado em 20 de fevereiro, 2009, de http://www.comicro.org.br/imgs/estudos/9-GEM-Empreendedorismo-noBrasil_2005.pdf.

Graevenitz, G., Harhoff, D., \& Weber, R. (2010). The effects of entrepreneurship education. Journal of Economic Behavior \& Organization, 76(1), 90-112.

Harper, D. A. (2008). Towards a theory of entrepreneurial teams. Journal of Business Venturing, $23(6), 613-626$.

Katz, J. (2003). The chronology and intellectual trajectory of American entrepreneurship education 1876-1999. Journal of Business Venturing, 18(2), 283-300.

Kuratko, D. F. (2009). The entrepreneurial imperative of the 21st century. Business Horizons, 52(5), 421-428.

Lima, A. L. (2008). Os riscos do empreendedorismo: a proposta de educação e formação empreendedora. Dissertação de Mestrado, Faculdade de Educação, Universidade de São Paulo, São Paulo.

Machado, H. V. (1999). Tendências do comportamento gerencial da mulher empreendedora. Anais do Encontro da Associação Nacional de Pós-Graduação e Pesquisa em Administração, 23 (pp. 1-8). Rio de Janeiro: ANPAD.

Martino, J. P. (1993). Technological forecasting for decision making ( ${ }^{\text {rd }}$ ed.). New York: Mc GrawHill.

McGrath, R. G., \& Macmillan, I. C. (2000). The entrepreneurial mindset. Boston: Harvard Business School Press.

Organização Internacional do Trabalho. (2001). Desemprego juvenil no Brasil: em busca de opções à luz de algumas experiências internacionais. Brasília: Autor.

Passos, C. A. K. et al. (2008). Empreendedores no Brasil - 2007. Recuperado em 15 de fevereiro, 2009, de http://www.gemconsortium.org/document.aspx?id=672.

Paterson, J. (2002). Tomorrow's job titles. The Futurist, 36(3), 9. 
Sarsur, A. M. (2001). Repensando a "empregabilidade", a "empresabilidade" e a "nova" gestão de recursos humanos: um estudo junto a organizações e profissionais em Minas Gerais [CD-ROM]. Anais do Encontro da Associação Nacional de Pós-Graduação e Pesquisa em Administração, 25. Rio de Janeiro: ANPAD.

Schlemm, M. M. et al. (2007). Empreendedorismo no Brasil: 2006. Curitiba: IBQP.

Schumpeter, J. A. (1984). Capitalismo, socialismo e democracia. Rio de Janeiro: Zahar.

Schumpeter, J. A. (1934). The theory of economic development. Cambridge: Harvard University Press.

Sela, V. M., Sela, F. E. R., \& Franzini, D. Q. (2006). Ensino do empreendedorismo na educação básica, voltado para o desenvolvimento econômico e social sustentável: um estudo sobre a metodologia "pedagogia empreendedora" de Fernando Dolabela [CD-ROM]. Anais do Encontro da Associação Nacional de Pós-Graduação e Pesquisa em Administração, 30. Rio de Janeiro: ANPAD.

Shane, S., Locke, E. A., \& Collins, C. (2003). Entrepreneurial motivation. Human Resource Management Review, 13(2), 257-279.

Usher, A. P. (1988). A history of mechanical invention. Mineola: Dover.

Wright, J. T. C., \& Giovinazzo, R. A. (2000). Delphi - uma ferramenta de apoio ao planejamento prospectivo. Caderno de Pesquisas em Administração, 1(12), 54-65.

THE LABOR MARKET IN THE FUTURE: A DISCUSSION ON INNOVATIVE PROFESSIONALS, ENTREPRENEURSHIP AND TRENDS FOR 2020

\begin{abstract}
Technological, organizational and market innovations are driving profound changes in the world of work. Some professions with innovative content have been created in order to keep pace with the changes. Structural changes in labor relations have also been observed. As a result of these changes, entrepreneurship has been the alternative to generate employment and income. In this context, this research sought to identify what will be the most probable careers in the future and where are the business opportunities for entrepreneurs, considering the year 2020. To this end, we used the Delphi technique, which enables the identification of trends and future events by using expert knowledge in a structured way. There were two rounds of consultation, with 96 respondents in Round 1 and 112
\end{abstract}


respondents in Round 2. The final results showed that the increasing emphasis on innovation, the search for life quality, the population aging and the concern with the environment will be important drivers in determining the most promising careers until 2020. It is envisioned a future in which we can interact with professionals such as Eco-Relations Managers, Chief Innovation Officers and Bioinformationists. Regarding entrepreneurship, experts projected a participation in the labor market in terms of Economically Active Population of 17\%. By the results, we can capture that there is an expectation of increasing the participation of entrepreneurial activities in the world of work in the future, which will coexist with the careers with innovative content identified in this study.

Keywords: Delphi technique; Careers of the future; Entrepreneurship.

Data do recebimento do artigo: 20/05/2010

Data do aceite de publicação: 25/07/2010 